\title{
Microstructural influences on the damage evolution and kinetics of high temperature hydrogen attack in a C-0.5 Mo welded joint
}

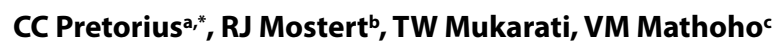 \\ Department of Materials Science and Metallurgical Engineering, University of Pretoria, cnr Lynnwood Road and Roper Street, \\ 0028 Hatfield, South Africa \\ Email: ${ }^{a} c c e p @ l i v e . c o . z a^{*}{ }^{b}$ Roelf.mostert@up.ac.za, ${ }^{c}$ moses.mathoho@sasol.com
}

\begin{abstract}
In the refining industry, steels can be susceptible to a damage mechanism known as high temperature hydrogen attack (HTHA). The detection of damage in such structures through non-destructive testing (NDT) requires insight into the damage development in various parts of welded joints. Once damage is detected, the tracking of the damage progression and estimation of remaining life is problematic. The performance of C- 0.5 Mo steels in such environments is also variable, and the current tendency is to regard the HTHA resistance of $\mathrm{C}-0.5 \mathrm{Mo}$ as similar to that of carbon steels. The current investigation explores the possibility of using high-temperature capsule strain-gauges for the in-situ evaluation of swelling - which generally accompanies HTHA in susceptible steels - and, thereby, evaluate the development and kinetics of HTHA damage for a C-0.5 Mo steel welded joint. Specimens were prepared representing the base metal (BM), the HAZ region, both fine-grained and coarse-grained, and the weld-metal (WM). The specimens were exposed to hydrogen at 200 bar at a temperature of $500{ }^{\circ} \mathrm{C}$ in an autoclave, with certain specimens fitted with high-temperature strain gauges; i.e. instrumented test labelled as IWM, IHAZ and IBM. Metallographic evaluation of the specimens - regarding the three locations mentioned - were performed; with exposure times reflecting both incipient and advanced damage. In the case of the base metal and the fine-grained HAZ, and after pronounced damage, macrocracks were observed. The orientation and location of these cracks were aligned with the rolling direction, and the cracks were evident in the through-thickness plane of the plate. It was found that the reason for this observation was due to preferential damage accumulation within banded regions, where high concentrations of carbides were observed. A sigmoidal equation was developed that described the swelling kinetics of the HAZ. The expression of swelling-induced strain rate (SISR) versus time showed a low initial SISR until incipient damage is formed, followed by accelerated attack. The peak SISR was observed midway through the damage evolution, where after the SISRs decreased as the presense of carbides - that feed the methane reaction - diminishes. It is proposed that the attachment of the encapsulated strain gauges to structures or components where HTHA damage is suspected, will assist in the tracking of damage and the estimation of remaining life; if used in conjunction with the developed sigmoidal equation.
\end{abstract}

Keywords: HTHA, C-0.5Mo, strain, HAZ, base-metal, weld-metal

\section{Introduction}

During high temperature hydrogen attack (HTHA), atomic hydrogen diffuses into the steel and react with carbides, forming methane and microcavities (Pillot \& Coudreuse, 2012). With continued exposure, the microcavities grow and join up to form microcracks, which later grow into macrocracks; compromising the structural integrity of process equipment. The HTHA volumetric damage process is associated with swelling or expansion of the steel, and linear variable differential transformers (LVDTs) have been used in previous work by Munsterman et.al. to track the damage process in the laboratory (Munsterman, Seijas. \& Williams, 2010).

In the design of vessels in hydrogen service and at elevated temperatures, operational envelopes regarding acceptable combinations of temperature, hydrogen pressure and steel type are provided in industry guidelines such as API RP 941. In the first editions of these guidelines, referred to as Nelson Curves, C-0.5 Mo steels were regarded as being more resistant to HTHA than carbon steels. The recommended temperatures and hydrogen pressures for C-0.5 Mo steels, according to the earlier editions of the Nelson curves, allowed operation at more onerous conditions compared to the recommendations for carbon steels. However, lately the HTHA performance of C-0.5 Mo steels is more uncertain and, therefore, current practice is that "most companies no longer specify C-0.5Mo steel for new or replacement equipment used in operation above the post weld heat treated carbon steel" boundaries of the Nelson Curves (API RP 941, 2016). Process equipment designed and constructed prior to the realization of these limitations of C- 0.5 Mo steels are, however, currently still in operation at operating conditions above the carbon steel curve. Frequent monitoring of such equipment is, therefore, critical; especially in the light of past catastrophic refinery failures due to $H T H A$, which resulted in safety incidents as well as loss and damage to equipment and, subsequently, high costs for replacement. Furthermore, it is also not clear to what extent the HTHA damage progression will differ in the various zones of a welded joint; i.e. the weld metal, base metal and heat affected zone. An improved understanding of the progression of HTHA in the various zones in a weld will be beneficial to direct NDT efforts in detecting damage during the early stages of attack. 
The fact that the HTHA damage process is associated with the expansion of the steel, implies that high-temperature strain gauges - when attached to the steel - can be used to track the damage process; both in the laboratory and within process equipment. High-temperature capsule-type strain gauges have recently been developed, which can be attached to the steel via capacitive discharge spot welding, and have been used successfully in power plant applications to track creep damage evolution. In the current research, these strain gauges were used to track the damage progression in the laboratory on samples taken from a C-0.5 Mo welded joint. The aim was to study the development and progression of HTHA damage in the various zones in a weld, and to quantitatively evaluate the damage process by monitoring the HTHA-induced swelling using the encapsulated strain gauges mentioned above. If the HTHA kinetics can be studied in the laboratory by using this technique, it should also be possible to use the same technique on process equipment. Furthermore, the use of the mathematical relationships describing the HTHA kinetics in the current study (laboratory conditions) should provide useful insights into on-site HTHA investigations, such as remaining life estimations; especially if used in conjunction with on-site hightemperature strain gauging.

\section{Material and methods}

A welded joint of a $69 \mathrm{~mm}$ thick ASME SA 302 Gr C plate which had formed part of a weld qualification procedure - was sourced for the machining of test specimens with dimensions of $10 \mathrm{~mm} \times 10 \mathrm{~mm} \times 34 \mathrm{~mm}$. Furthermore, material was also sourced to machine specimen jigs and a strain gauge calibration specimen; refer to Table I for the chemistry of the plate material. Samples were removed from the weld metal zone, the base metal zone, and the heat affected zone; designated respectively as BM, WM and HAZ hereafter. The orientation of the samples was such that the longitudinal axis was parallel to the rolling direction of the plate.

Table I: Analysed chemistry of the provided ASME SA $302 \mathrm{Gr}$ $\mathrm{C}$ base plate material (in $\mathrm{wt} \%$ )

\begin{tabular}{ccccccccc}
\hline $\mathbf{C}$ & $\mathbf{M n}$ & $\mathbf{S i}$ & $\mathbf{M o}$ & $\mathbf{N i}$ & $\mathbf{P}$ & $\mathbf{S}$ & $\mathbf{A l}$ & $\mathbf{F e}$ \\
\hline 0.18 & 1.32 & 0.26 & 0.48 & 0.53 & 0.006 & 0.001 & 0.02 & Rem. \\
\hline
\end{tabular}

High-temperature capsule-type strain gauges were attached to the samples via capacitive discharge spot welding (CDSW). The instrumented samples were placed within an autoclave and the strain gauge leads were taken out through the pressure envelope. After performing a stress relief heat treatment, the autoclave, with sample, was taken to a temperature and hydrogen pressure well above the carbon steel Nelson Curve; in order to accelerate the HTHA process. All samples were polished to a 1-micron surface finish prior to exposure.

For the HAZ test specimen, a smaller specimen was machined from the weldment to produce a sample that comprised of only the coarse grained (CGHAZ) and fine grained HAZ (FGHAZ) microstructures. The HAZ was marked out from the original specimen using optical microscopy (OM), and a smaller specimen (dimensions of $2 \mathrm{~mm} \times 10 \mathrm{~mm} \times 32 \mathrm{~mm}$ ) fully comprising of $H A Z$ material was sectioned by EDM machining. Figure 1 is a photograph of the instrumented HAZ-specimen/JIG assembly used for autoclave testing. A similar process was followed for the WM sample to arrive at a final specimen size of $2.5 \mathrm{~mm}$ x $32 \mathrm{~mm}$ x 10 mm. (see Figure 2).

\section{Calibration procedure}

An ambient-temperature calibration test was performed in order to confirm the correct variables for the strain-gauge measurements. For this test, a rectangular tensile specimen was machined from plate material that included a welded joint. The machined tension specimen had a parallel gauge-length of $57 \mathrm{~mm}$, with cross-sectional dimensions of $10 \mathrm{~mm} \times 10 \mathrm{~mm}$. Furthermore, the specimen was machined such that the softer weld-metal was positioned at the centre of the gauge-length. One high-temperature (capsule) straingauge was attached via $C D S W$, and was positioned over the weldmetal. The specimen was then installed into an MTS Criterion 45 test system. An extensometer (50mm gauge length) was installed, connecting to the surface opposite to that of the strain-gauge (refer to Figure 3 (i)). Various tensile loads were applied to the specimen, and the extensometer, strain-gauge and load readings were tabulated and used to produce the tensile calibration curve in Figure 3 (ii).

From Figure 3 (ii) it is clear that very good correlation exists between the extensometer and the strain-gauge strain values

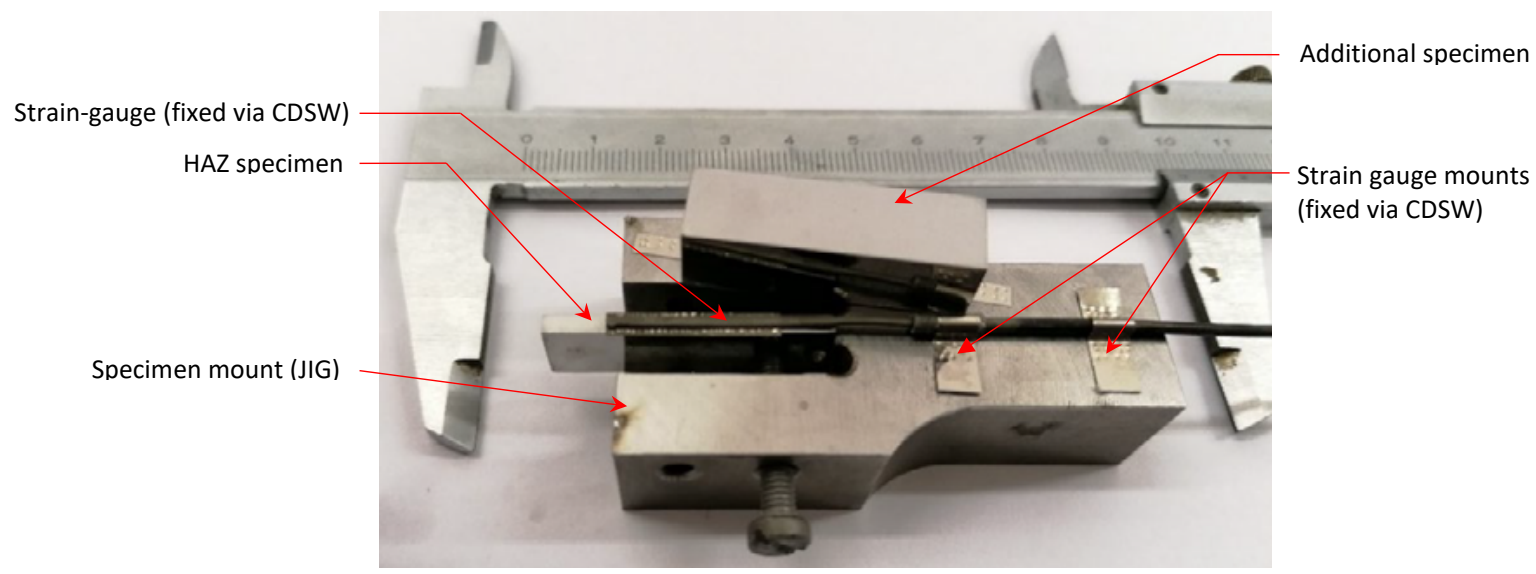

Figure 1: Photograph of the HAZ specimen-strain-gauge assembly fixed to the specimen holder. Additional specimens were also subjected to the relevant temperatures and hydrogen partial pressures, with a view to facilitate microstructural evaluations. 


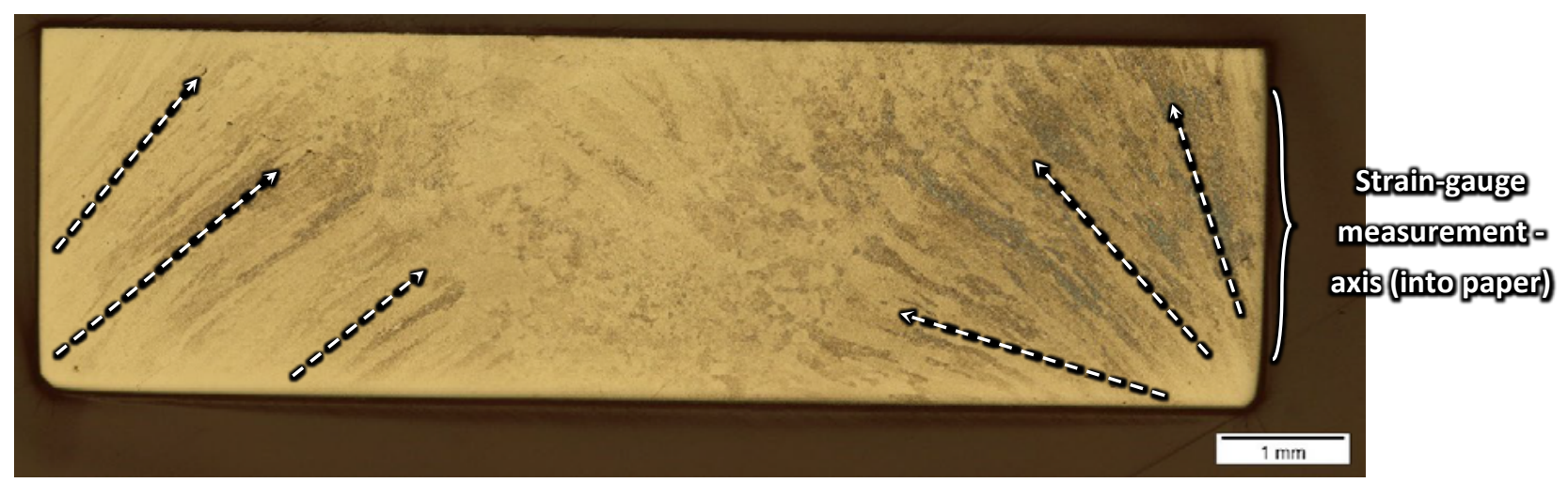

Figure 2: Overview of the $I W M$ specimen along the specimen depth, showing the orientation of the columnar grains (dashed arrows) with regards to the strain-gauge measurement-axis (into the paper).

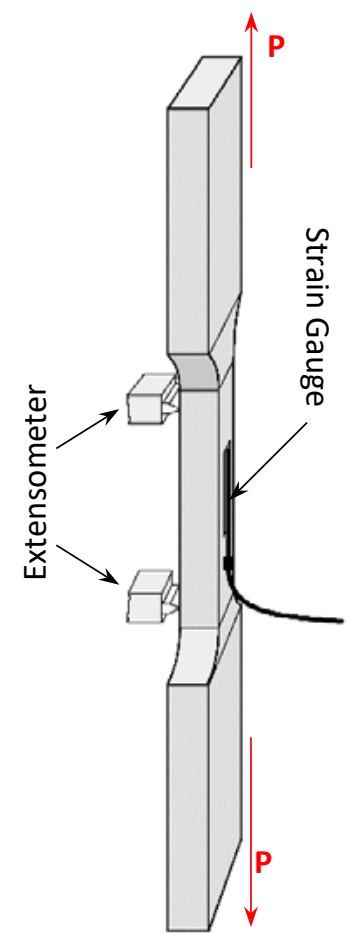

(i)

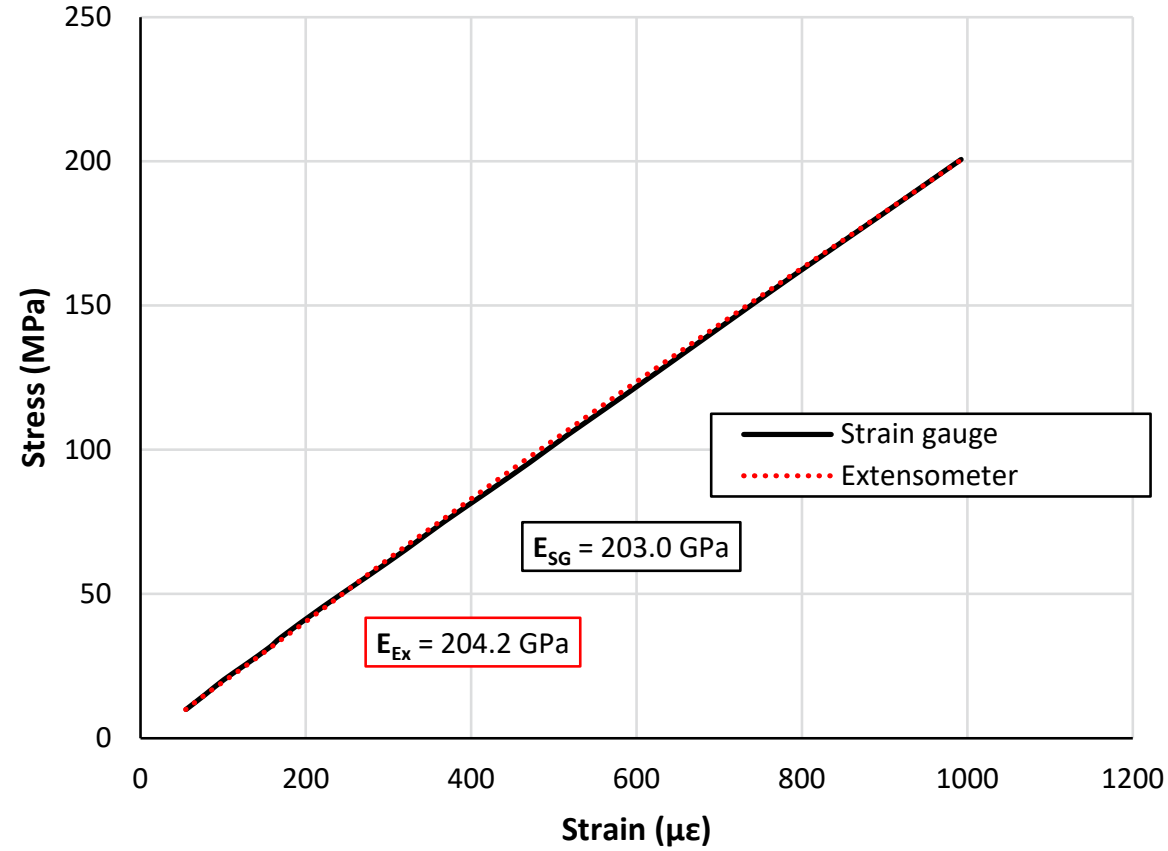

(ii)

Figure 3: Calibration test run results, with (i) a schematic showing the position of the strain gauge (10mm gauge length) and extensometer (50 mm gauge length) with regards to the applied load (P), and (ii) the comparative stress-strain results and calculated Young's moduli for the extensometer and strain-gauge data.

for a given applied load (stress). The elastic moduli of both the extensometer $\left(\boldsymbol{E}_{\boldsymbol{E} x}\right)$ and strain-gauge $\left(\boldsymbol{E}_{\boldsymbol{S G}}\right)$ fall well within the expected range of 190 to $210 \mathrm{GPa}$ for the alloy, and only revealed a small difference in the respective values. This may be explained by the lower sensitivity of the extensometer as compared to the strain-gauge. The results gave certainty with regards to the use of a bridge factor of 1.0 , as well as certainty that the required cutting and reconnecting of the strain-gauge leads - to facilitate passing of the lead through the autoclave head - resulted in insignificant alterations in the strain-gauge readings. The method used would allow the re-use of the capsule strain gauge and sample after EDM of a section of the gauge length.

\section{Results}

\subsection{Metallography of the unexposed samples (as received, $\mathbf{A R}$ )}

\subsubsection{Base Metal}

The as-received $(A R)$ microstructures of the base metal samples reveal a tempered martensite structure; finely dispersed spherical carbides can be observed within - and at the grain-boundaries of - ferritic grains (Refer to Figure 4 and Figure 5). Evidence of remaining laths are clearly visible throughout the ARBM microstructure, as indicated with label (b) in Figure 4. Furthermore, segregation bands (labelled (a) in Figure 4(i)) with higher carbide densities are also visible throughout the microstructure. 


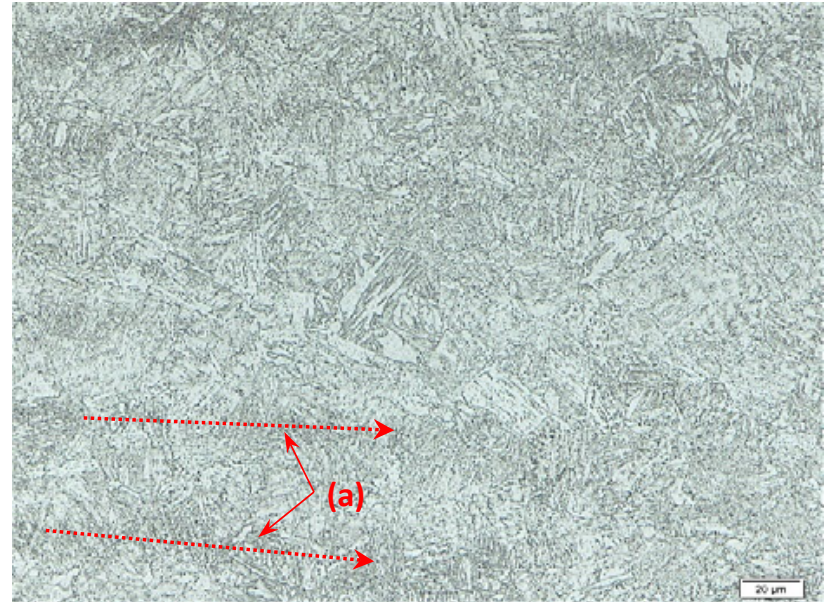

(i)

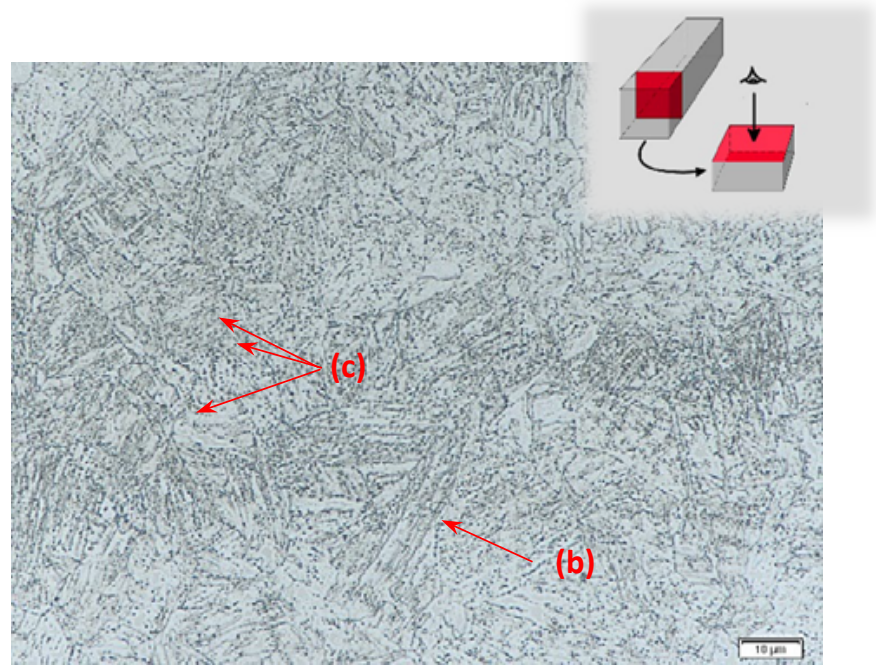

(ii)

Figure 4: Optical micrographs of the as-received $B M$ samples at (i) $500 X$ nominal magnification, and (ii) $1000 X$ nominal magnification.

Note the evidence of remaining laths (labelled (b)) in the tempered martensite structure; with the latter consisting of fine carbides (black, labelled (c)) dispersed within (and at the grain-boundaries of) the ferrite grains. Additionally, note the segregation bands (labelled (a)) with higher carbide densities; indication of initial rolling direction prior to the heat treatment.

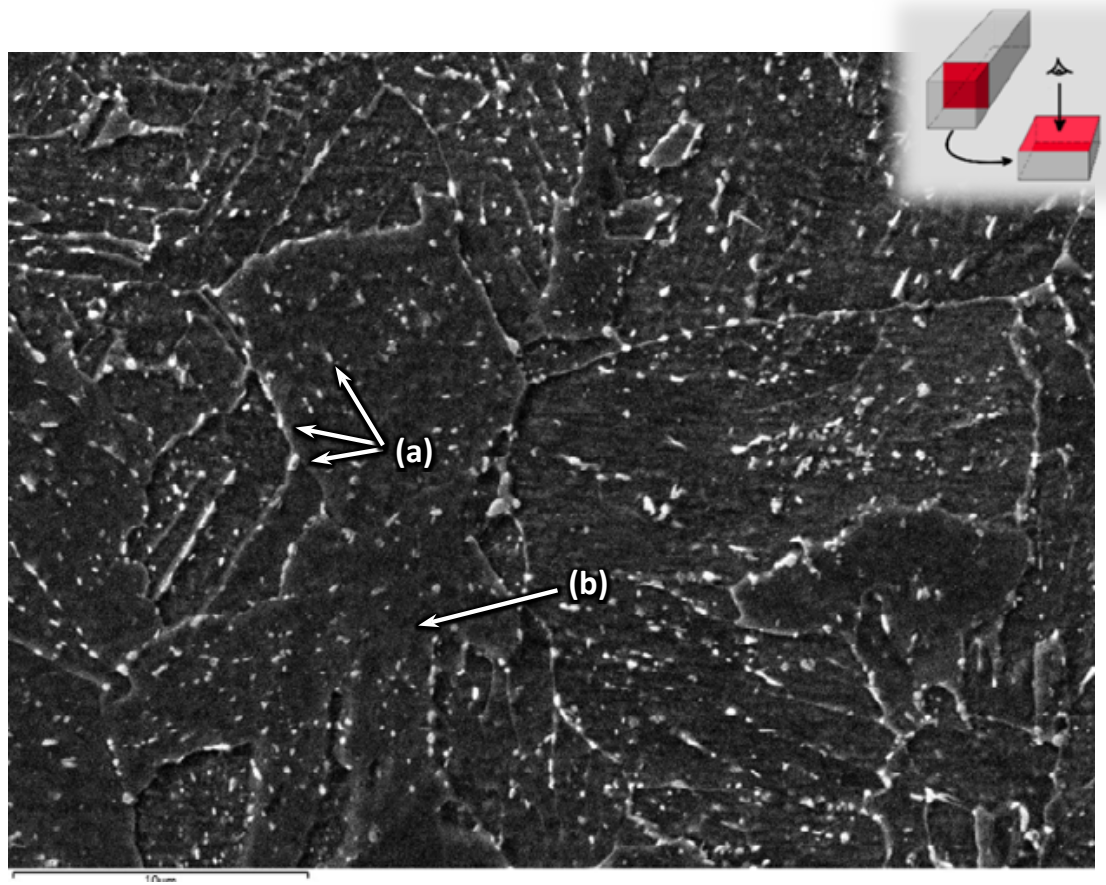

Figure 5: SEM micrograph of the as-received $B M$ samples, showing the tempered martensite structure, with finely dispersed carbides (white labelled $(a)$ ) at the ferrite (black labelled (b)) grain boundaries, as well as within the ferrite grains.

These bands could have formed due to the classical banding mechanisms associated with segregation during solidification, followed by breaking up of the dendritic structure during hot rolling. The presence of these bands was found to be significant in the current investigation; they essentially provide a "memory quality" pertaining to the hot rolling stages of the manufacturing process, and act as localisation regions for HTHA damage. The scanning electron micrograph in Figure 5 illustrates the same $A R B M$ structure at a higher magnification and resolution.

Figure 6: (right) Optical micrograph of the as-received weld metal $(A R W M)$ at $500 \mathrm{X}$ nominal magnification, showing evidence of relatively long columnar (prior-austenite) grain-boundaries (labelled (a)) at which the ferritic grains nucleated and grew.

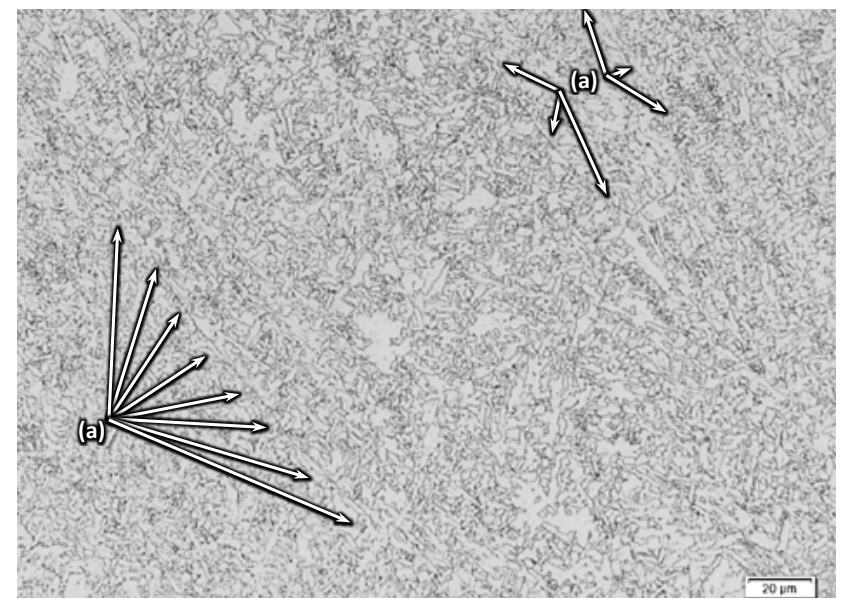




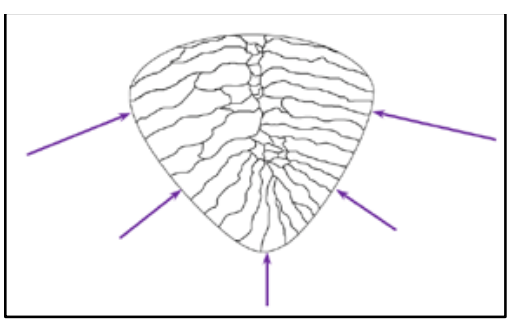

Figure 7: Simple schematic of the weld bead columnar microstructure, showing that the growth direction of the columnar (prior-austenite) grains follows the direction of the thermal gradient. Note; the purple arrows indicate both the growth direction, and the thermal gradient (cold to hot).

\subsubsection{Weld Metal}

The metallographic evaluation of the as-received weld-metal (ARWM) shows evidence of lengthy columnar grains (refer to label (a) in Figure 6). During the weld metal solidification process, these columnar grains grew in the direction of the thermal gradient introduced during welding (refer to Figure 7). These grains comprise of smaller ferritic grains with carbides readily found at the grain boundaries.

\subsubsection{Heat-Affected Zone:}

From the metallographic evaluation of the as-received heat-affected zone (ARHAZ), three transition zones could be distinguished; that is, (i) the solid-liquid transformation zone, which generally comprises of untempered martensite and defies the transition from weld metal to the re-austenitised, coarse grained HAZ (CGHAZ), (ii) a second
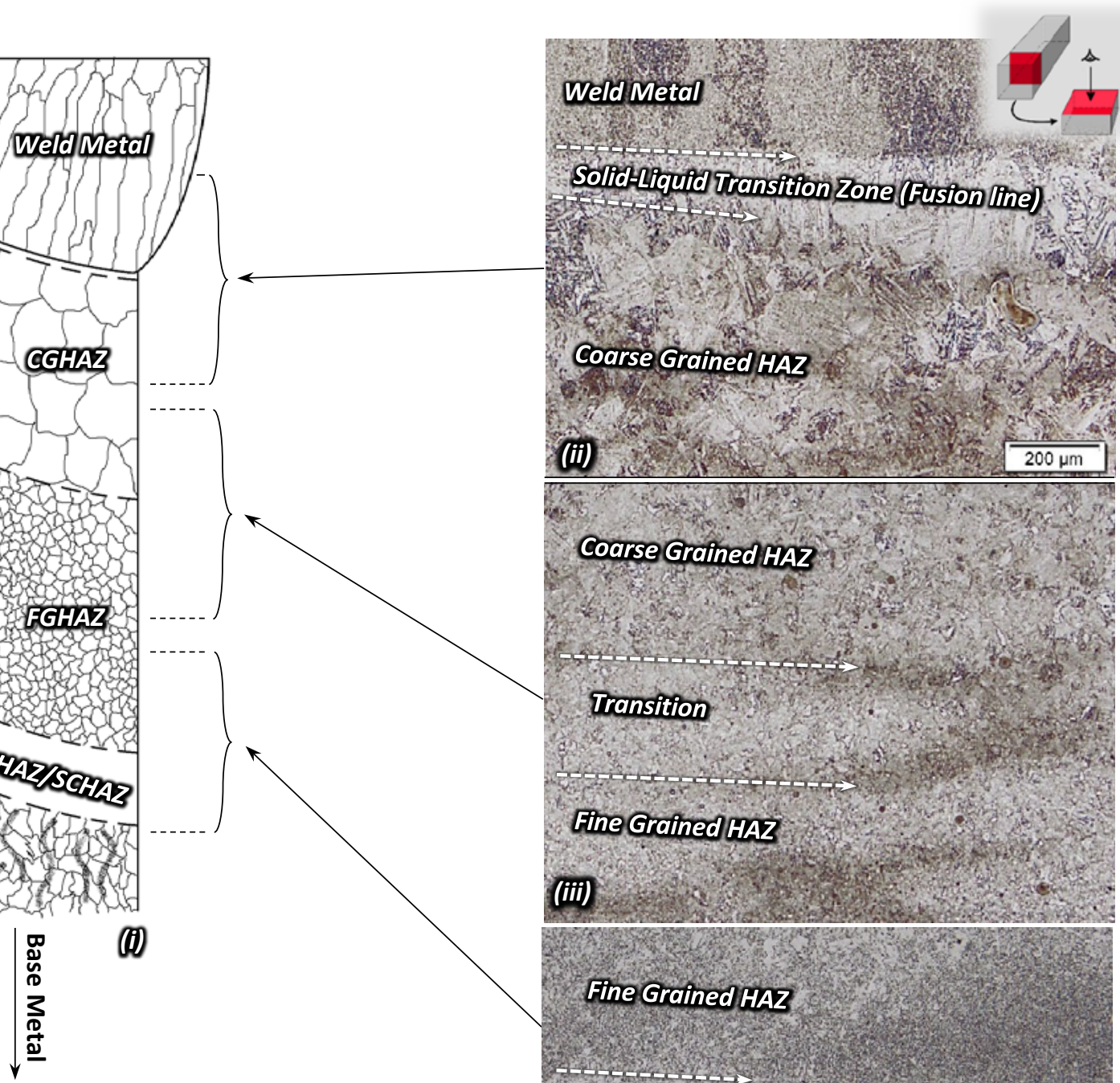

Figure 8: Metallographic evaluation of the heat-affected zone of the provided SA302 Gr C welded specimens; with (i) a schematic representation (not to scale) of the variation in the metallographic structures, and (ii) through (iv) the micrographs associated with transition regions, as indicated (Note: (ii) and (iii) have the same scale bar (50 X nominal magnification), but (iv) has a larger nominal magnification of $200 X)\{($ i) adopted from Smith et.al., 2019\}.

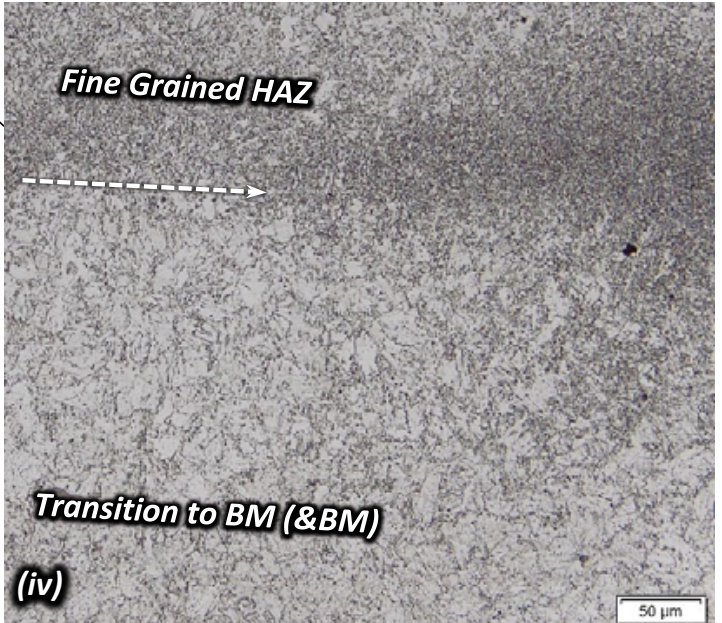




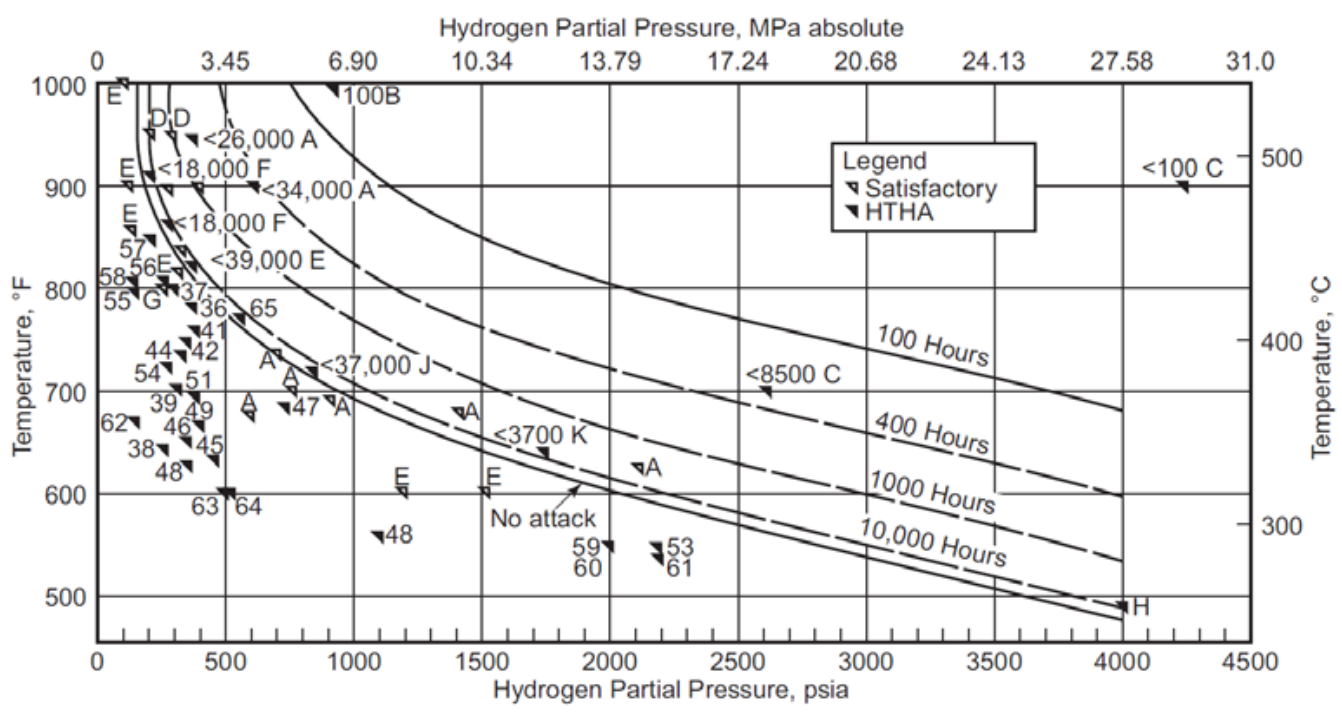

Figure 9: Time to incipient attack for C -0.5 Mo steels according to API RP 941: 2016

transition from the $C G H A Z$ to a fine grained (recrystallized) HAZ ( $F G H A Z$ ), and finally (iii) the transition from the $F G H A Z$ to the normal $B M$ structure. Note that the transition from $F G H A Z$ to the $B M$ may include the inter-critical (IC) and sub-critical (SC) $H A Z$ regions shown in Figure 10(i).

\subsection{First Exploratory Autoclave Runs}

The Nelson Curves for various exposure durations, including 100 hours, are shown in Figure 9 (API RP 941, 2016). Accordingly, it would be expected that initiation of HTHA damage would occur after the 100 hour exposure of the samples to a hydrogen partial pressure of 100 bar at $500^{\circ} \mathrm{C}$. Samples of all three regions of the weld were exposed and evaluated through OM and SEM at magnifications of up to 31000 times. No damage could be observed for the samples; probably indicating that the considered steel has superior resistance to HTHA. Using the same exposure temperature, the samples were subsequently exposed for another 113 hours at a higher hydrogen pressure of 192 bar. Thereafter, metallography was done again on the samples.

\subsubsection{Microstructural Investigation following exploratory run, Base Metal}

The base metal microstructure, at a magnification of 2000X, did not yield clear evidence of HTHA damage (refer to Figure 10(i)). However, the high-resolution SEM photographs (refer to Figure 10 (ii) and (iii)) show evidence of microcavity formation at carbides on ferrite grain boundaries (labelled (a) in Figure 10(ii) and (iii)), as well as of decohesion and microcracking at the ferrite grain boundaries (labelled (b) in Figure 10(ii) and (iii)).

Figure 10: (right)SEM micrographs of the BM test runs after exposure to hydrogen partial pressures of 103 bar ( 98 hours), followed by 113 hours at 192 bar, at a temperature of $500^{\circ} \mathrm{C}$; (i) at a nominal magnification of $2000 \mathrm{x}$, with (ii) a higher magnification $(\approx 30,74 \mathrm{KX}$ nominal) micrograph of Detail $A$ in (i) and (iii) a higher magnification $(\approx 10,00 K X$ nominal) micrograph of Detail B in (i).

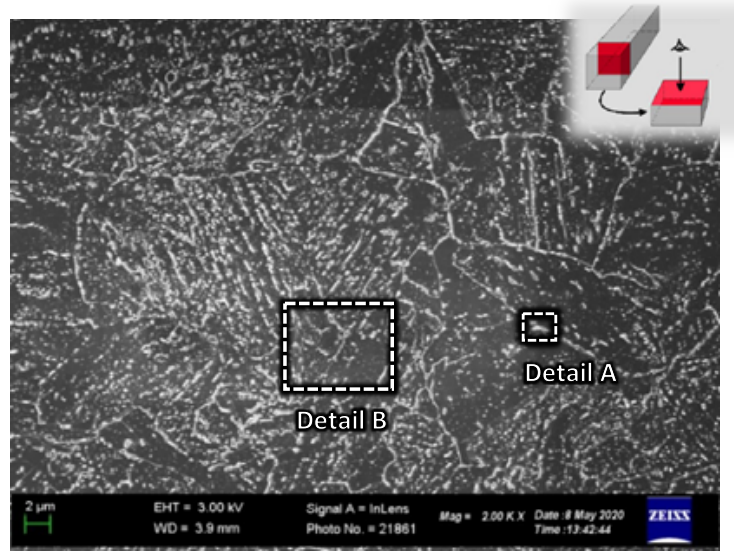

(i)

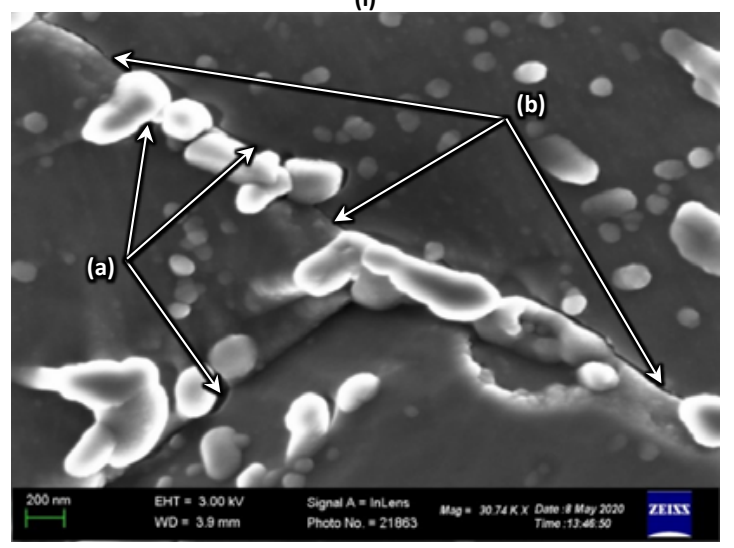

(ii) Detail A

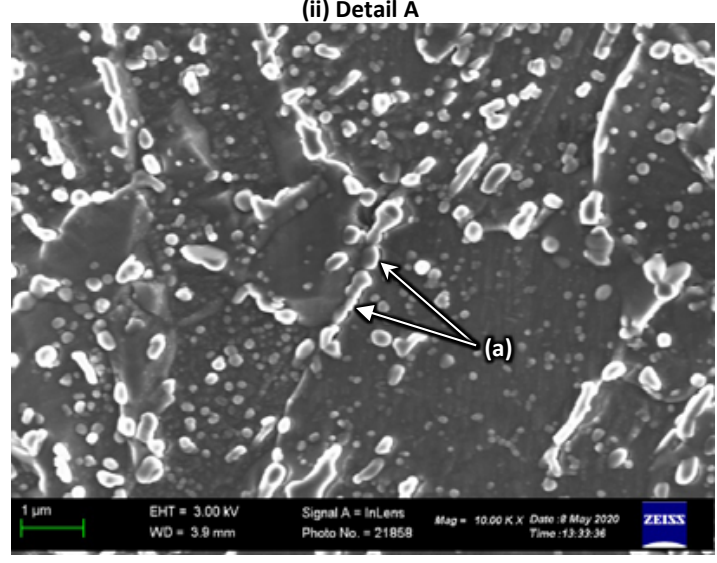




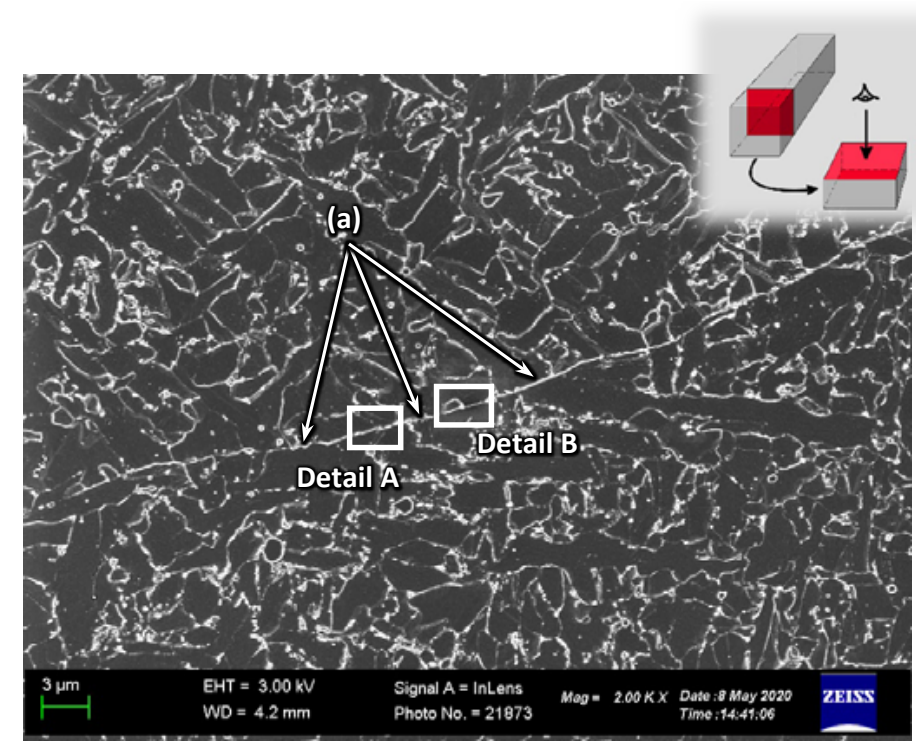

(i)
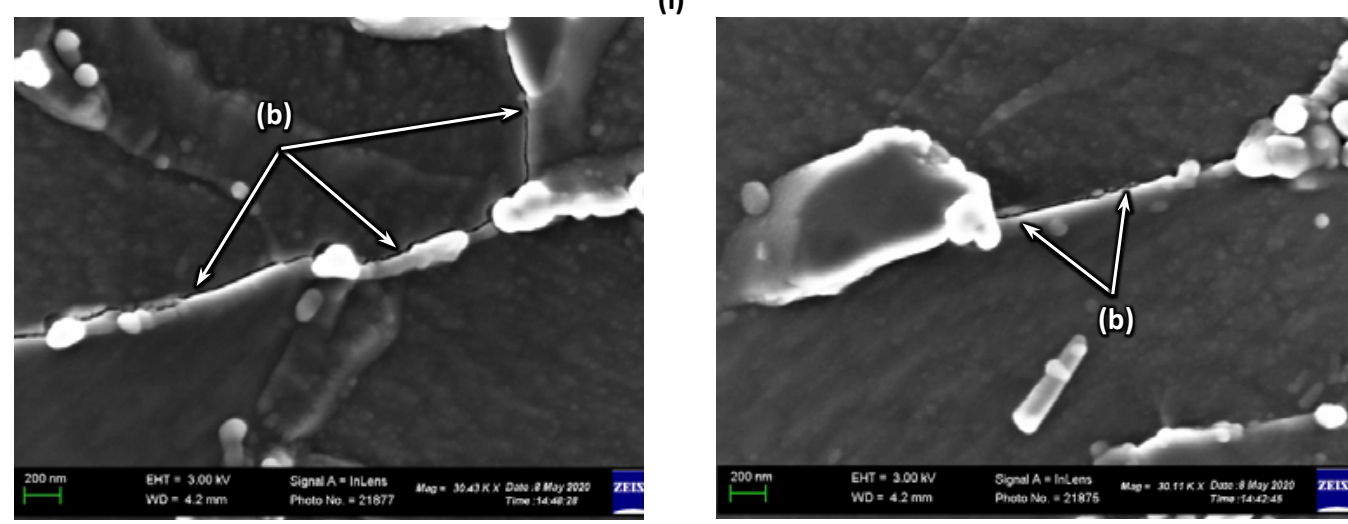

Figure 11: SEM micrographs after the WM test runs; with (i) a relatively low magnification $(2000 X)$ micrograph showing the columnar grain-boundary (or $P A G B$, labelled (a)). (ii) and (iii) are higher magnification $(\approx 30 K X)$ micrographs of Detail $A$ and Detail $B$ respectively. Note the microvoid formation adjacent to carbides, as well as the microcracking linking the carbides along the PAGBs.

\subsubsection{Microstructural Investigation following exploratory run, Weld Metal}

As with the $A R B M$, damage was only visible using high magnifications $(\approx 30000$ nominal magnification). Additionally, the damage was only detected after the full 211 hour exposure at $500^{\circ} \mathrm{C}$; i.e. the $98 \mathrm{~h}$ at $103 \mathrm{bar}$ exposure, along with the additional 113 hour exposure at 192bar. The high-resolution SEM micrographs of the completed UIWM test run can be seen in Figure 11. Note that the damage (labelled (b)) preferentially took place along the prior-austenite grain-boundaries ( $P A G B S$, labelled (a)). From a theoretical viewpoint, this makes good sense: During the solidification and heat treatment processes of the weld metal, impurities (such as S, P and N) and other alloying elements (e.g. C) are known to segregate towards these grain boundaries, resulting in concentration gradients that peak on the boundary surfaces. As such, the necessary fuel (i.e. carbon) for high temperature hydrogen attack may be present more abundantly at these grain-boundaries; not only in the form of carbides, but also in the form of interstitial 'free' carbon.

\subsubsection{Microstructural Investigation following exploratory run, Heat-Affected Zone}

The $H A Z$ test runs provided substantial information using optical microscopy. Substantial attack was observed near the solid-liquid transformation region (fusion-line) and the CGHAZ of the $H A Z$ structure (refer to Figure 12(ii)). Distinct microcracks were noted along the $P A G B s$ of the $C G H A Z$ and fusion-line. The fusion line generally revealed a lighter shading after etching (refer to Figure 12(ii)), which is believed to indicate the presence of untempered martensite in these coarse-grained structures. The carbide banding which was observed for the $B M$ samples, was not evident for the as-received sample for the $C G H A Z$.

Metallographic evaluation of the $F G H A Z$ also revealed evidence of early HTHA damage in the form of grain-boundary carbide attack (refer to Figure 13 (ii)). In this case, the observed damage was limited to the formation of microvoids adjacent to carbides on ferrite grain boundaries, and could be identified at moderate magnifications. The carbide banding - which was observed for the $B M$ samples - was also evident for the as-received FGHAZ sample as well.

The metallographic results, therefore, demonstrated that exposure at $500^{\circ} \mathrm{C}$ and 200 bar hydrogen pressure would be suitable for the instrumented runs.

\subsection{Instrumented test runs}

All samples were prepared as outlined in the "Materials and Methods" section, and was subsequently exposed in an autoclave 


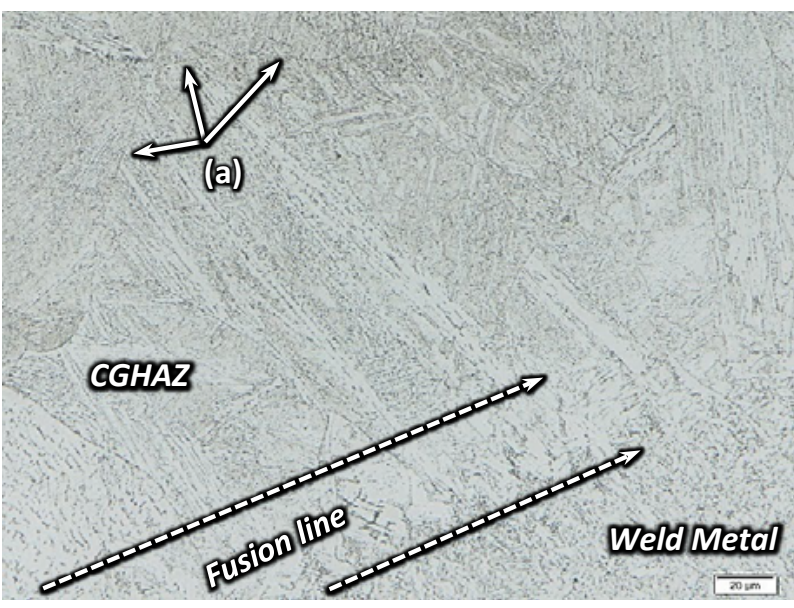

(i)

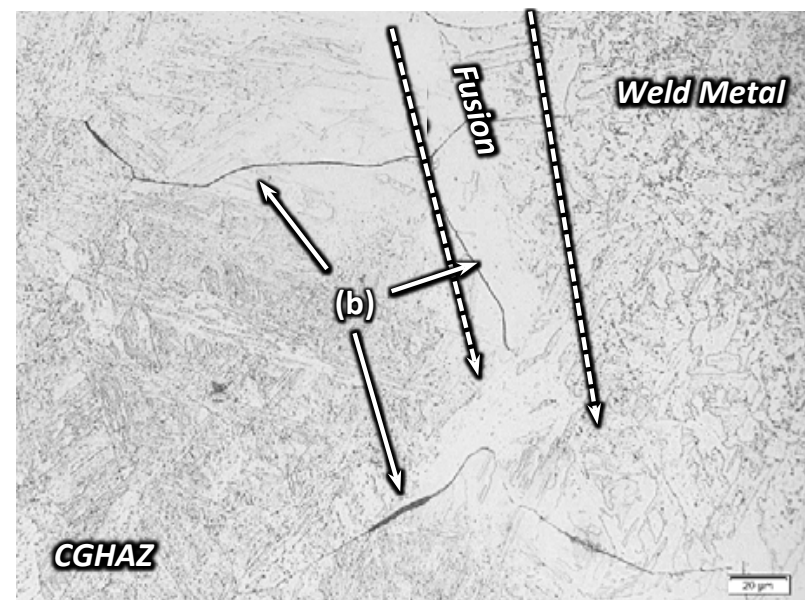

(ii)

Figure 12: Optical micrographs ( $500 X$ nominal magnification) of the $H A Z$ specimens, comparing (i) the as-received microstructure to that of (ii) the fully exposed, $H A Z$ test run near the solid-liquid transformation region (fusion-line). Note the coarse-grained structure $(P A G B$, labelled (a) in (i)) of the solid-liquid transformation region, and the significant HTHA microcracking (labelled (b) in (ii)) that occurred along the $P A G B S$ in the fusion line region.

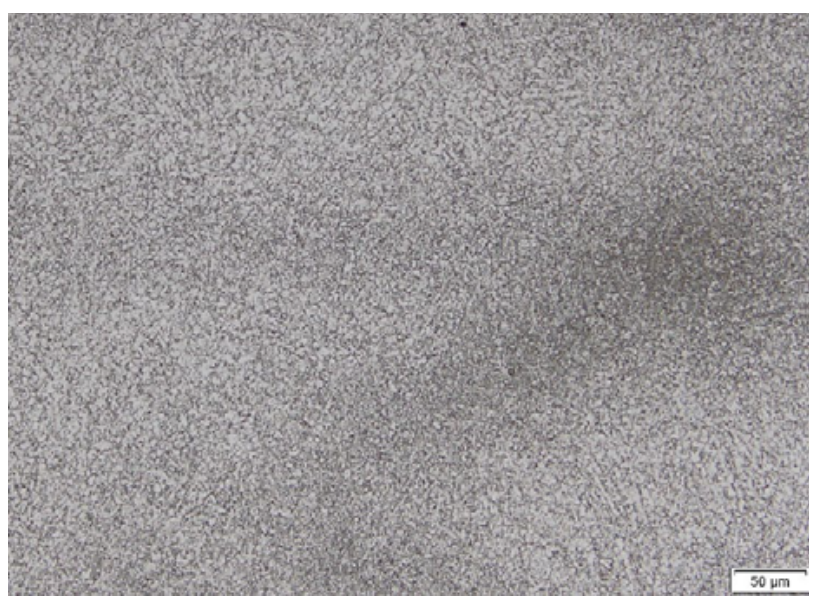

(i)

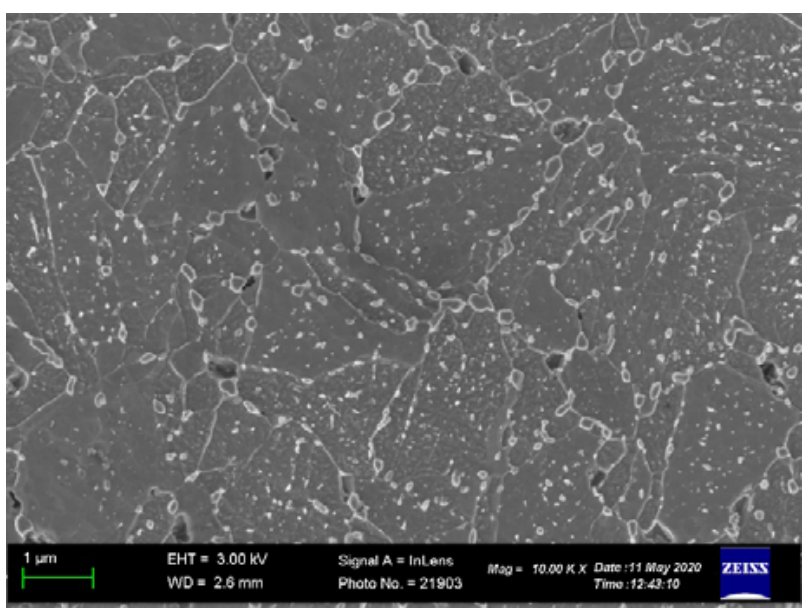

(ii)

Figure 13: Micrographs of the fine-grained $(F G) H A Z$ region, with (i) a low magnification (200X nominal) optical micrograph of the $F G H A Z$ prior to exposure, showing a higher proportion of carbides in certain bands. Figure 12 (ii) is a high-resolution SEM micrograph after the 211 hour exposure at a significant magnification of $10 \mathrm{KX}$ (nominal).

containing hydrogen at 200 bar at $500^{\circ} \mathrm{C}$. Swelling was continuously monitored until the swelling rate reduced to zero. Thereafter, the test was stopped and the samples were sectioned for metallographic evaluation. The swelling results (i.e. the strain measured due to the swelling induced by HTHA) of the instrumented autoclave test runs for the three regions are presented in Figure 14.

The microstructure of the $B M$ sample, following the full exposure, is shown in Figure 15. Long fissures with clear crack-face separation were observed in a direction at right angles to the plane in which the encapsulated strain gauge was located. The fissures grew along the direction of the afore mentioned segregation bands, and extensive decarburization has occurred adjacent to the fissures. Peak swelling is expected to occur perpendicular to the length of the fissures, indicating that swelling anisotropy will be present in this morphology (refer to Figure 15). It is also important to note that the strain-gauge measurement axis (coming out of the page in Figure 15) was parallel to the fissures; that is, perpendicular to the peak swelling direction.
Optical microscopy of the $W M$ specimen, following the full exposure, showed continuous microcracking along the columnar $P A G B s$; evident at relatively low magnification (Figure 16). However, the carbides within the prior-austenite grains (i.e. at the small ferrite-grain boundaries) appeared to be relatively unaffected. The microcrack wall separation, as well as the overall level of decarburization were both small as compared to the $B M$ test run. Once again, the peak swelling is expected to be perpendicular to the fissures.

From the cross-sectional view of the WM test specimen (as was shown in Figure 2), the issue with measuring the peak swelling becomes evident. That is, there exists no single direction that would suffice for the measurement of the peak swelling strain. This is due to the fissures forming along the columnar prior austenite grain boundaries, which are orientated towards the original weldinduced thermal gradient. As such, swelling anisotropy is also present in the weld metal; however, it is more difficult to predict the swelling anisotropy in the case of the $W M$ as compared to the $B M$. 


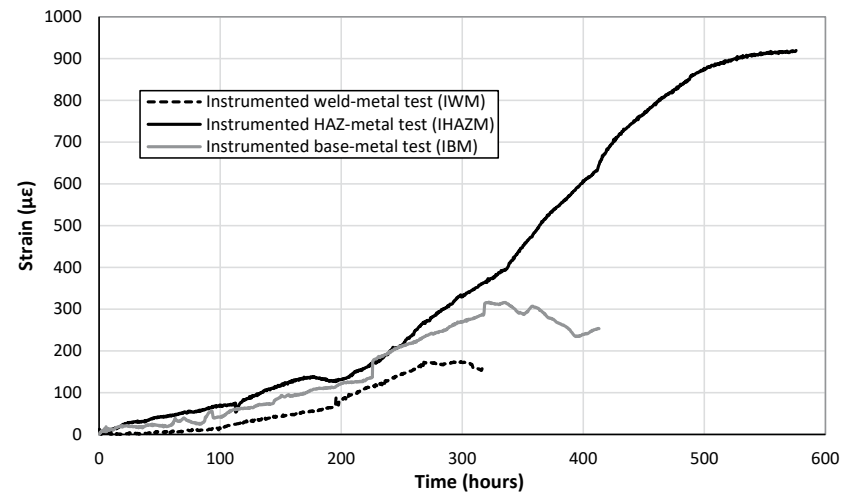

Figure 14: Results of the measured swelling in the $W M$ (dashed), $H A Z$ (solid-dark) and $B M$ (solid-grey) of SA302 Gr C specimens during exposure to a hydrogen partial pressure of $200 \mathrm{bar}$ at $500^{\circ} \mathrm{C}$ for the relevant times, as measured with the encapsulated strain gauges.

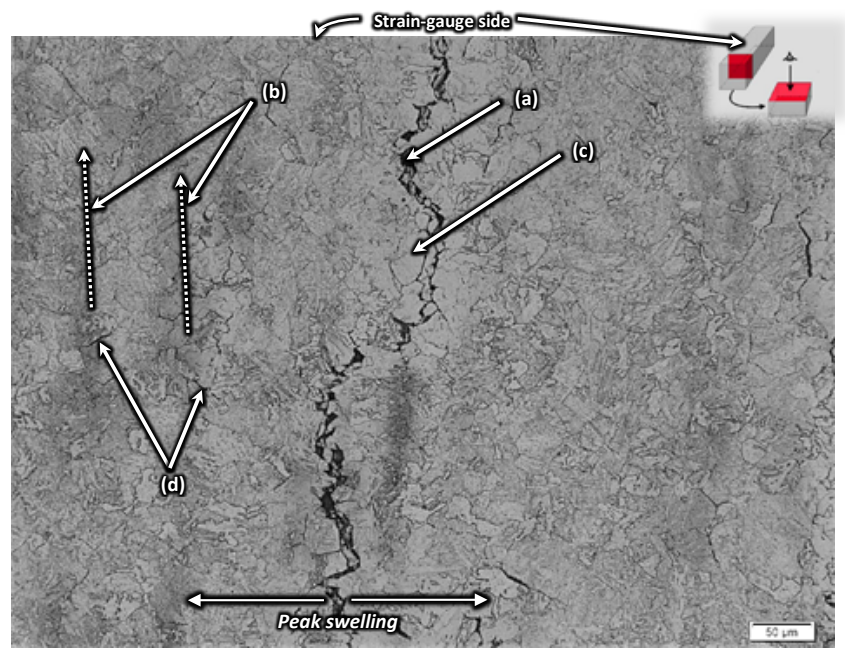

Figure 15: Post $H T H A$ test micrograph (200X nominal magnification) of the $I B M$ specimen after full exposure showing significant fissuring (labelled (a)) parallel to the direction of the segregation bands (labelled (b)). Note the decarburization (labelled (c)) adjacent to the main fissure, as well as the formation of new micro cracks (labelled (d)) within the segregation bands.

For the fully exposed $H A Z$ sample at the FGHAZ region, low magnification OM revealed what appeared to be carbides lying in bands parallel to the strain gauge surface (refer to label (a) in Figure 17). However, higher magnification $O M$ (refer to Figure 18) revealed extensive decarburisation, along with an extensive network of microvoids which had coalesced to form the thick bands seen in Figure 17. As with the $B M$, the damage was found at the locations that previously comprised of higher carbide densities; i.e. the segregation bands. However, due to the manner in which the damage manifested (the formation and growth of microvoids in all directions before ultimately linking up to form the thick band of voids), the anisotropic effect as seen in the $B M$ and $W M$ is expected to be significantly reduced in the FGHAZ.

Finally, microscopy of the CGHAZ also revealed extensive decarburization, along with a significant presence of cracking along the prior austenite grain boundaries (refer to Figure 19). These were oriented in all directions and, as such, the CGHAZ material condition is expected to not exhibit the swelling anisotropy found in the $W M$ and $B M$.

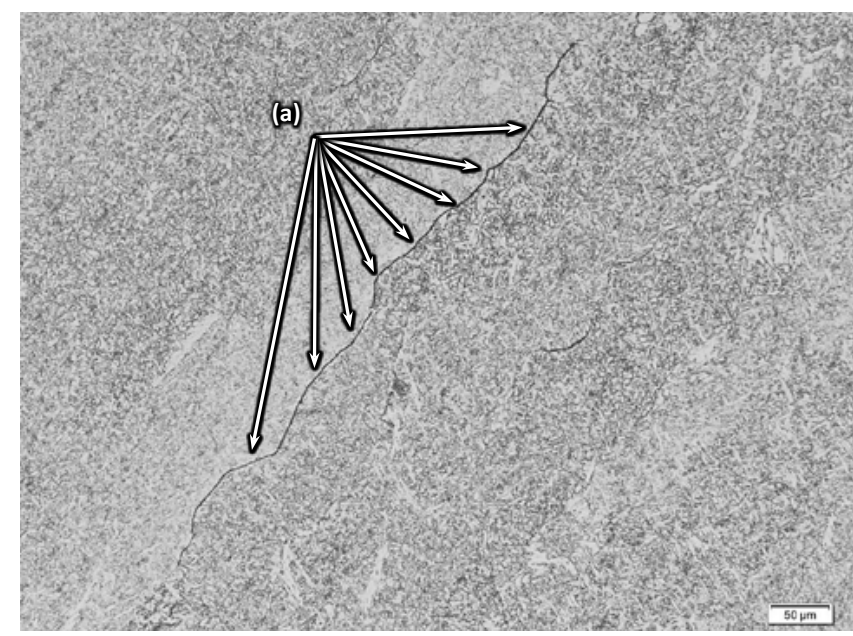

(i)

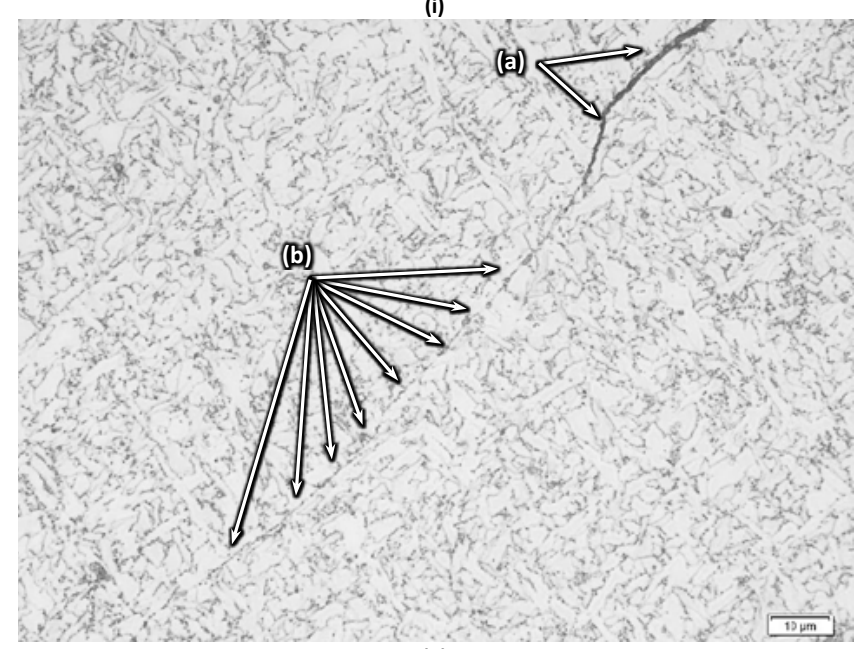

(ii)

Figure 16: Micrographs ((i) at $200 X$ nominal magnification and (ii) at $1000 \mathrm{X}$ nominal magnification) of the weld-metal after 316 hours of exposure; showing HTHA damage (labelled (a)) along the $P A G B s$ (labelled (b)).

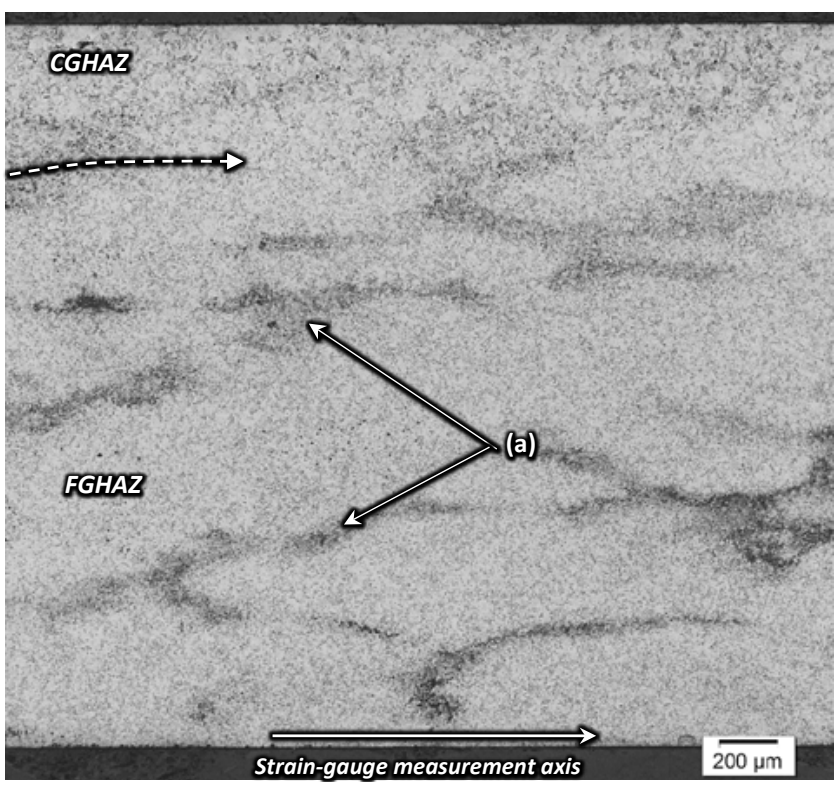

Figure 17: Optical micrograph (50X nominal magnification) of the HAZ specimen after 577 hours of exposure to a hydrogen partial pressure of $200 \mathrm{bar}$ at $500^{\circ} \mathrm{C}$; showing an overview of the CGHAZ and the FGHAZ after HTHA. Note; the significant networking of $H T H A$ damage in the FGHAZ resulting in high width fissuring (dark shading labelled (a)) that follows the original rolling-direction. 


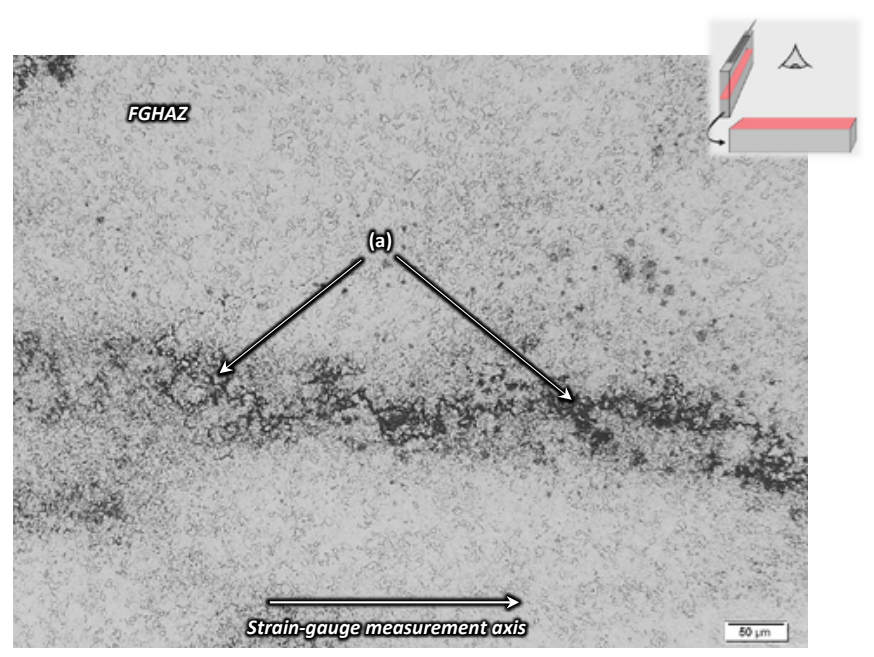

Figure 18: Optical micrograph (200X nominal magnification) of the FGHAZ after 577 hours of exposure to a hydrogen partial pressure of $200 \mathrm{bar}$ at $500^{\circ} \mathrm{C}$, showing the networking of HTHA damage resulting in high width fissuring (labelled (a)) along the original rolling direction. Note; evidence of complete decarburisation.

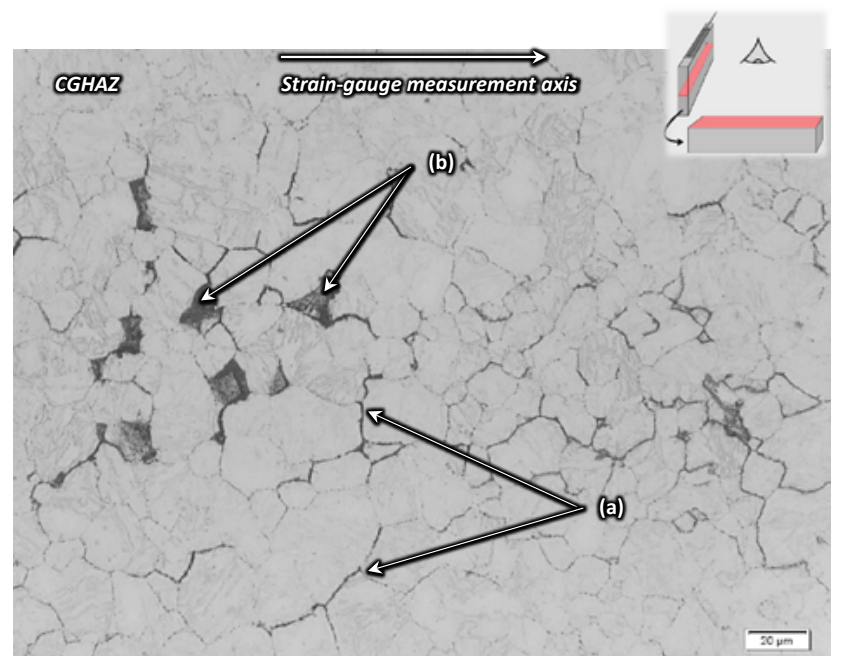

Figure 19: Optical micrograph (500X nominal magnification) of the $C G H A Z$ after 577 hours of exposure to a hydrogen partial pressure of 200 bar at $500^{\circ} \mathrm{C}$, showing $H T H A$ damage along the grain-boundaries of the coarse-grained structure (labelled (a)). Note; the full cohesion of some grains (labelled (b)) and evidence of complete decarburization.

Table II: The presence of visible macrocracking on the material surfaces following full exposure to a hydrogen pressure of $200 \mathrm{bar}$ at $500^{\circ} \mathrm{C}$ (examined at $8 \mathrm{X}$ nominal magnification)

\begin{tabular}{lll}
\hline $\begin{array}{l}\text { Weld } \\
\text { Location }\end{array}$ & $\begin{array}{l}\text { Evidence } \\
\text { of Visible } \\
\text { MacroCracks }\end{array}$ & $\begin{array}{l}\text { Orientation and location of } \\
\text { cracks }\end{array}$ \\
\hline Base Metal & Yes & $\begin{array}{l}\text { Parallel to the length of } \\
\text { sample, in the through- } \\
\text { thickness plane of the plate }\end{array}$ \\
\hline CG HAZ & No & $\begin{array}{l}\text { - } \\
\text { FG HAZ }\end{array}$ \\
& Yes & $\begin{array}{l}\text { Parallel to the length of } \\
\text { sample, in the through- } \\
\text { thickness plane of the plate }\end{array}$ \\
\hline Weld metal & No & - \\
\hline
\end{tabular}

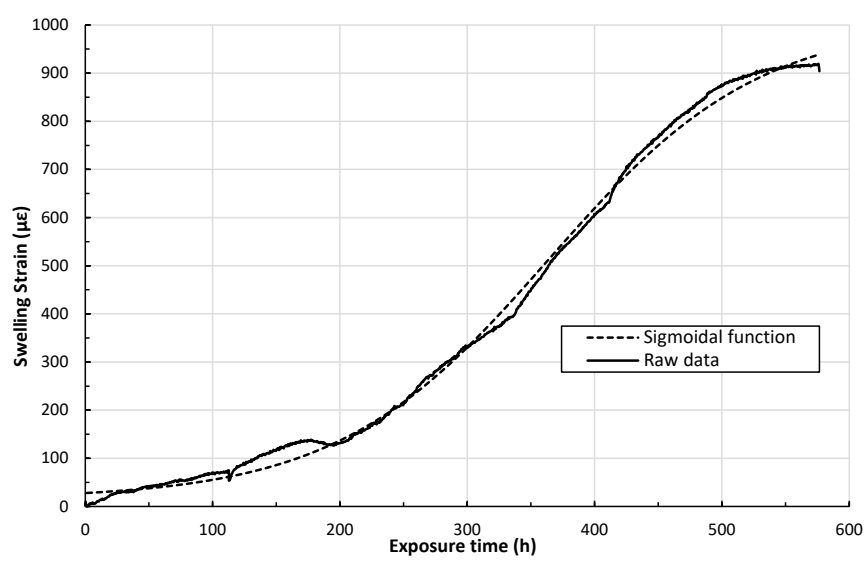

Figure 20: Comparison of the calculated swelling strain (according to the sigmoidal fit, dashed line) and the experimental HAZ data (solid line), for the C-0.5 Mo HAZ sample

The development of macrocracks is important from a structural integrity perspective. After the completion of the exposure, the polished specimen surfaces were examined for the presence of macrocracks. The criteria used was visibility of cracks at a nominal magnification of 8 times in the unetched condition. A summary of the presence of macrocracks is given in Table II.

\subsection{Mathematical equation describing HTHA kinetics}

The HAZ HTHA swelling curve shows a typical sigmoidal shape. Other authors, using LVDTs, have also published sigmoidal curves (Munsterman, Seijas. \& Williams, 2010). However, they have not developed mathematical equations to describe the HTHA strainlife behaviour.

The fitting of a sigmoidal equation to the HAZ data resulted in the following equation;

$$
\varepsilon=A_{2}+\left[\frac{A_{1}+A_{2}}{1-\exp \left(\frac{t-x_{0}}{d x}\right)}\right]
$$

eq (1), $R^{2}=0.997$ (see Figure 20)

with the constants $A_{1}$ and $A_{2}$ calculated to have the values of 15.57 and 1009 micro-strain respectively. $x_{0}$ is the time corresponding to the maximum reaction or swelling rate (see Figure 21), and is found to be 363.81 hours for the $H A Z$ material. Finally, $d x$ is an inverse rate constant, and is calculated to be 83.02 hours.

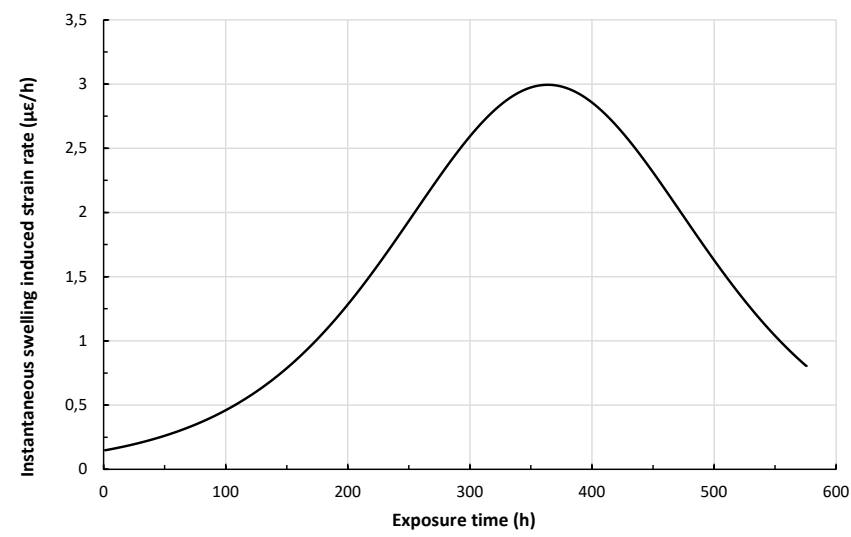

Figure 21: The instantaneous strain rate (swelling induced) for the C-0.5 Mo HAZ region as a function of time; according to the sigmoidal fit described by equation 1 . 
Additionally, if the data of the first 175 hours is considered to be a linear portion, with a strain rate of $0.73 \mu \varepsilon / \mathrm{h}$, a slightly improved sigmoidal correlation is found for the remaining data; i.e. $\mathrm{R}^{2}=$ 0.998 , with $\mathrm{A}_{1}=90.88 \mu \varepsilon, \mathrm{A}_{2}=967.6 \mu \varepsilon, \mathrm{x}_{0}=371.3$ hours, and $\mathrm{dx}=66.25$ hours. The latter approach provides more conservative strain rate results, with a higher peak strain rate of $3.3 \mu \varepsilon / \mathrm{h}$, whilst not overestimating the strain rate at the end of the cycle.

\section{Discussion}

The study demonstrated that the extent and nature of the HTHA damage evolution differed greatly in the various zones of the welded joint.

In the early stages of attack, the $B M$ damage was limited to carbides on the ferrite grain boundaries, where microvoids and microcracking could be observed at high magnification (see Figure 10). In contrast, attack of the $W M$ morphology was limited to regions where the carbides precipitated on the columnar (prior-austenite) grain boundaries. This attack was limited to isolated regions, in which the presence of the resulting microvoids and microcracking could only be microscopically identified at very high magnification (see Figure 11). Free energy considerations favour the formation of gas bubbles on grain boundaries rather than within the matrix (Greenwood, 1968). The same authors have shown that lenticularshaped bubbles on grain boundaries - removing sections of a grain boundary and causing damage appearing as a microcrack - are to be expected from free energy and surface energy principles.

The early stages of attack in the $C G H A Z$ region was characterised by continuous microcracking of the grain boundaries, which could readily be identified using $O M$ (Figure 12). The fine-grained region of the $H A Z$ showed small microvoids adjacent to carbides on ferrite grain boundaries (Figure 13). Furthermore, it was noted that, for this steel, considerably more aggressive conditions were required to develop incipient attack as compared to those published in standards (refer to Figure 9); indicating superior resistance to HTHA.

In the advanced stages of attack, after completion of the exposure shown in Figure 14, the extent and nature of the HTHA damage evolution, again, differed significantly in the various locations of the welded joint. In the base metal, regions with full decarburization and macrocracking were observed (Figure 15). The macrocracks were orientated along the direction of the segregation bands (lying in the length-axis of the sample), with the consequence that the strain gauge measurements would not have indicated the full extent of the swelling. This is due to the peak swelling expected to occur perpendicular to the crack orientation, whilst the strain gauge measurement axis followed the direction of cracking. The location of the macrocracks in the through-thickness plane, and the reason why they are parallel with the rolling direction, is explained by the carbide banding that was observed.

Macrocracking (visible at 8 times magnification) was not evident in the concluded $W M$ run. However, microcracking was evident along the columnar grain boundaries (refer to Figure 16), and were mostly oriented at an inclined angle to the plane of the strain gauge measurement; see the macro photograph of the weld metal and the columnar grain orientation in Figure 2. This has the consequence that the strain gauge measurement - shown in Figure 14 - would also not reflect the maximum swelling for the weld metal. In addition, a significant volume fraction of carbides could be observed after the conclusion of the instrumented autoclave run, indicating incomplete methane formation (refer to Figure 14).

In the case of the FGHAZ, decarburisation was advanced and extensive networking of microvoids were observed. The orientation and location of these microvoid networks are also ascribed to the carbide bands. This is due to the relatively low temperatures experienced by the FGHAZ during welding, which did not allow for the dissolution of said carbides. As such, these regions provide an abundance of the fuel (carbides) needed for the reaction to continue. Additionally, due to the manner in which the damage manifested, it is also believed that swelling anisotropy would be significantly lower within the $F G H A Z$ as compared to the $B M$ and $W M$.

The CGHAZ, however, showed no macrocracks, but rather extensive grain boundary cracking and full decarburisation (refer to Figure 19). Many of the microcracks were oriented at right angles to the rolling direction and the strain gauge measurement axis, with the consequence that the swelling-time curve shown for the $H A Z$ (Figure 14) can be regarded as representing the full extension of the $C G H A Z$ region. The fact that the microcracks in this region are not preferentially oriented in the carbide banding planes, is attributed to the high temperatures reached here during the welding operation. That is, the high temperatures would have been sufficient to dissolve the carbides, destroying the banding. It is, furthermore, clear that the methane reaction in this region has run to completion.

The finding that the HTHA kinetics can be described by a sigmoidal equation is significant in terms of life monitoring of structures which are being degraded by $H T H A$. In such cases, the progress of HTHA damage can be assessed using capsule-type strain gauges - attached through $C D S W$ to the components being monitored. The extent of full swelling for the CGHAZ in the structure will be represented by the term $\left(A_{2}-A_{1}\right)$ in equation 1 . Once incipient attack is detected, and when increasing levels of swelling strain is measured, the constants $\mathrm{x}_{0}$ and $\mathrm{dx}$ can be calculated by iterative curve fitting of the data. In this way, the progress of the damage can be continuously tracked, and future damage accumulation can be predicted. Therefore, the use of this type of strain gauge in remaining life evaluations holds significant promise. However, strain gauge application will have to be preceded by metallographic replication; to identify banding planes and the hot rolling direction of the plates or profiles in question.

The shape of the strain rate vs. time curve, shown in Figure 21, provides insight into the kinetics of the HTHA damage evolution process. Initially, the rate of the development of damage and its associated swelling is slow as microvoids are formed adjacent to grain boundary carbides. Microcracks with minimal face separation develop, joining adjacent grain boundary carbides, with low swelling resulting (see Figure 10 (ii)). This stage can be regarded as incipient attack, with the typical microstructures as shown in Figures 10 to 13 . As the microvoids grow and the microcrack face separation increases due to the internal methane pressure, the 
strain rate increases and grain boundary carbides along with the free carbon are consumed by the hydrogen present. This process becomes increasingly rapid up to a specific time, represented by $\mathrm{x}_{0}$ in equation 1 and the time associated with the peak strain rate in Figure 21. At this point, microvoids and microcracks have formed at many locations within the microstructure, and rapid growth is fuelled by the abundance of damage sites and the internal methane pressure resulting in pore growth. Beyond this peak, the strain rate decreases as the availability of carbides to feed the methane reaction diminishes. With further increases in time, the strain rate increasingly diminishes as full decarburisation and the absence of carbides and free carbon are approached.

\section{Conclusions}

- The HTHA damage progression of a C-0.5 Mo steel may be tracked using encapsulated high temperature strain gauges; attached to the steel using capacitance discharge spot welding.

- A sigmoidal mathematical equation successfully describes the HTHA damage evolution and kinetics. The strain gauge method and equation could possibly be utilized for in-situ tracking and remaining life evaluation of HTHA damage in structures.

- The microstructural manifestation of both incipient and advanced HTHA damage significantly differs in the various weld locations.

- After completion of the accelerated HTHA runs, macrocracks were observed in the case of the base metal, and void networking was observed in the fine-grained HAZ. These were oriented in the rolling direction and it was found that crack initiation was associated with the attack of clustered carbides which were located in banded regions. Such attack was not evident in the coarse-grained HAZ and weld metal zones, which revealed cracking along the prior austenite grain boundaries.

- The orientation of the strain gauge relative to certain microstructural constituents, such as banding or columnar grains, influences the strain gauge readings significantly. That is, swelling anisotropy is revealed in some of the morphologies.

\section{Funding Sources}

The work was largely funded by Sasol (Pty) Ltd.

\section{Contribution of each author}

RJ Mostert and VM Mathoho conceptualised the study. CCE Pretorius performed the experiments, with RJ Mostert providing supervision. CCE Pretorius and RJ Mostert wrote the first drafts of the manuscript. TW Mukarati performed the mathematical analysis of the strain vs time (swelling) curves. All authors contributed to the review and are satisfied with the final paper.

\section{References}

1. API RP 941, 2016, Steels for Hydrogen Service at Elevated Temperatures and Pressures in Petroleum Refineries and Petrochemical Plants., $8^{\text {th }}$ Ed., American Petroleum Institute (API).

2. Greenwood, G., 1969. The Solubility of Gas Bubbles, Journal of Material Science, Volume 4. pp 320-322

3. Munsterman, T., Seijas, A. \& Williams, P., 2010. High Temperature Hydrogen Attack Resistance Using Autoclave Testing of Scoop Samples. IPELA $14^{\text {th }}$ Annual Conference. 4 February.

4. Pillot, S. \& Coudreuse, L., 2012. Hydrogen-Induced Disbonding and Embrittlement of Steels Used in Petro-Chemical Refining. In: Gaseous Hydrogen Embrittlement of Materials in Energy Technologies: The Problem, its Characteristics and Effects on Particular Alloy Classes.

5. Smith, A., Asadikiya, M., Yang, M., Chen, J. \& Zhong, Y., 2019. An Investigation of Creep Resistance in Grade 91 Steel through Computational Thermodynamics. Journal of Engineering, Volume 6. p 1016 